\title{
Gastric calcifying fibrous tumour
}

\author{
Tan Attila MD ${ }^{1}$, Dean Chen MD FRCPC ${ }^{1}$, Geoffrey W Gardiner MD FRCPC ${ }^{2}$, \\ Theadore W Ptak MD FRCPC ${ }^{3}$, Norman E Marcon MD FRCPC ${ }^{1}$
}

\section{T Attila, D Chen, GW Gardiner, TW Ptak, NE Marcon. Gastric calcifying fibrous tumour. Can J Gastroenterol 2006;20(7):487-489.}

\begin{abstract}
Intramucosal gastric tumours are most commonly found to be gastrointestinal stromal tumours or leiomyomas (smooth muscle tumours); however, a variety of other uncommon mesenchymal tumours can occur in the stomach wall. A rare benign calcifying fibrous tumour is reported and the endoscopic appearance, ultrasound findings and morphology are documented. A review of the literature found only two similar cases.
\end{abstract}

Key Words: Endoscopic ultrasound; Fibroma; Laparascopic resection; Submucosal polyp

$\mathrm{C}^{\mathrm{a}}$ alcifying fibrous tumours are rare, benign lesions characterized by hypocellular, densely hyalinized collagenization with lymphoplasmacytic infiltrations, as described by the World Health Organization (1). Psammomatous and/or dystrophic calcifications are hallmarks of these lesions. In 1988, these lesions were originally described by Case Western University (Ohio, USA) pathologists under the name of childhood fibrous tumours with psammoma bodies (2). Five years later, Fetsch et al (3) reported 10 additional cases affecting pediatric as well as young adult patients. The lesions were originally described as arising in the subcutaneous and deep soft tissues (2,3). Recently, calcifying fibrous tumours have been reported in various locations, such as the mesentery and peritoneum (4-8), pleura (9-12), mediastinum (13), lung (14), adrenal glands (15), and paratesticular and spermatic cord (6). Although calcifying fibrous tumours have been reported in various organ systems, involvement of the gastrointestinal (GI) tract is extremely rare. To our knowledge, there are only two case reports $(16,17)$ of this lesion involving the stomach. We describe the third case report of calcifying fibrous tumour found in the gastric wall.

\section{CASE PRESENTATION}

A 47-year-old Caucasian woman was seen by her primary care physician for a six-month history of halitosis. The patient denied the use of tobacco products but admitted to social drinking. She did not use prescribed or over-the-counter medications. She had no malaise, chest pain, palpitations, heartburn, dysphagia, weight loss, early

\section{Une tumeur fibreuse calcifiante gastrique}

Les tumeurs gastriques intramuqueuses sont surtout des tumeurs stromales gastro-intestinales ou des léiomyomes (des tumeurs des muscles lisses). Cependant, toute une série d'autres tumeurs mésenchymateuses rares peuvent se manifester sur la paroi de l'estomac. Une tumeur fibreuse calcifiante rare et bénigne est déclarée, et son apparence endoscopique, les constatations échographiques et sa morphologie sont documentées. Une analyse bibliographique n'a permis de découvrir que deux cas similaires. satiety, altered bowel habits, hematemesis or melena. Past medical history included a breast lumpectomy for a fibroadenoma. Her physical examination was unremarkable.

A barium examination of her upper GI tract revealed a round defect impinging on the lumen, which was suggestive of a gastric polyp at the junction of the distal lesser curvature and antrum. Gastroscopy revealed a $2 \mathrm{~cm} \times 2 \mathrm{~cm}$ distal lesser curvature bulge with normal overlying mucosa (Figure 1). Mucosal biopsies showed chronic gastritis secondary to Helicobacter pylori, with no evidence of a neoplastic process. Computed tomography with contrast revealed two, small, hypodense lesions representing hemangiomas at liver segments 5 and 7 . Remaining organs, including the stomach, pancreas and gallbladder were normal, without any evidence of retroperitoneal, abdominal, pelvic or inguinal lymphadenopathy. Endoscopic ultrasound of the gastric mass (Figure 2) showed a focal hypoechoic lesion involving the mucosal layers. Within the lesion, hyperechoic foci with shadowing consistent with calcifications was noted. The depth of the lesion could not be determined due to the shadowing artifact produced by calcification. A laparoscopic gastric wedge resection of the gastric wall lesion was performed. Pathological examination revealed an intramural, discrete, white nodule with a maximum tumour dimension of $3.2 \mathrm{~cm}$. Microscopy showed a hypocellular, spindle-celled tumour with densely hyalinized, collagenous matrix, scattered lymphoplasmacytic aggregates (Figure 3) and a few foci of psammomatous and dystrophic calcifications (Figure 4). Immunostaining for vimentin was positive; c-kit (CD117), CD34, desmin, actin

${ }^{1}$ Division of Gastroenterology, Center of Therapeutic Endoscopy and Endoscopic Oncology; ${ }^{2}$ Department of Pathology, University of Toronto, Saint Michael's Hospital; ${ }^{3}$ Division of Gastroenterology, Humber River Regional Hospital, Toronto, Ontario

Correspondence and reprints: Dr Norman E Marcon, Saint Michael's Hospital, 16-062 Cardinal Carter Wing, 30 Bond Street, Toronto,

Ontario M5B 1W8. Telephone 416-864-3092, fax 416-864-5993, e-mail Norman.marcon@utoronto.ca

Received for publication December 25, 2005. Accepted January 23, 2006 


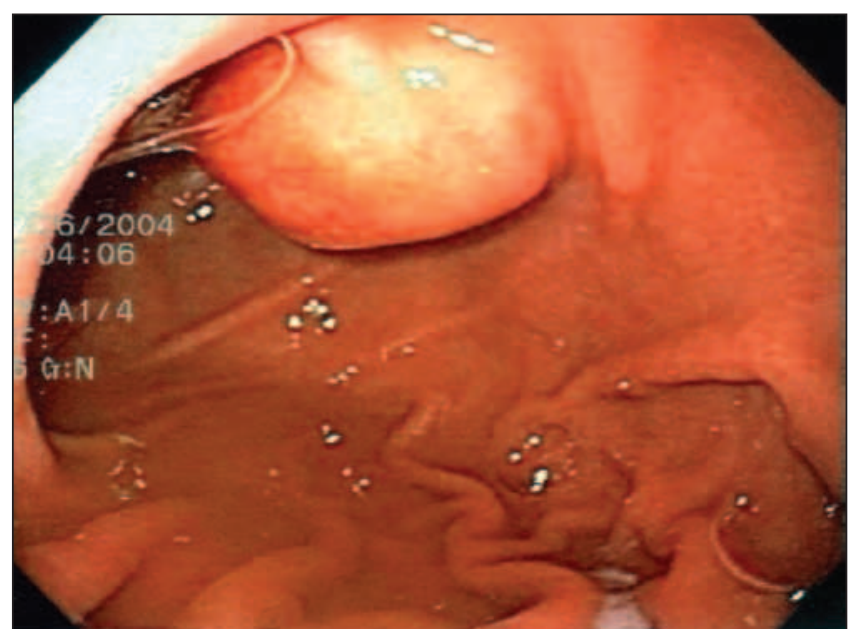

Figure 1) Endoscopic view of the gastric submucosal mass, with normal overlying mucosa

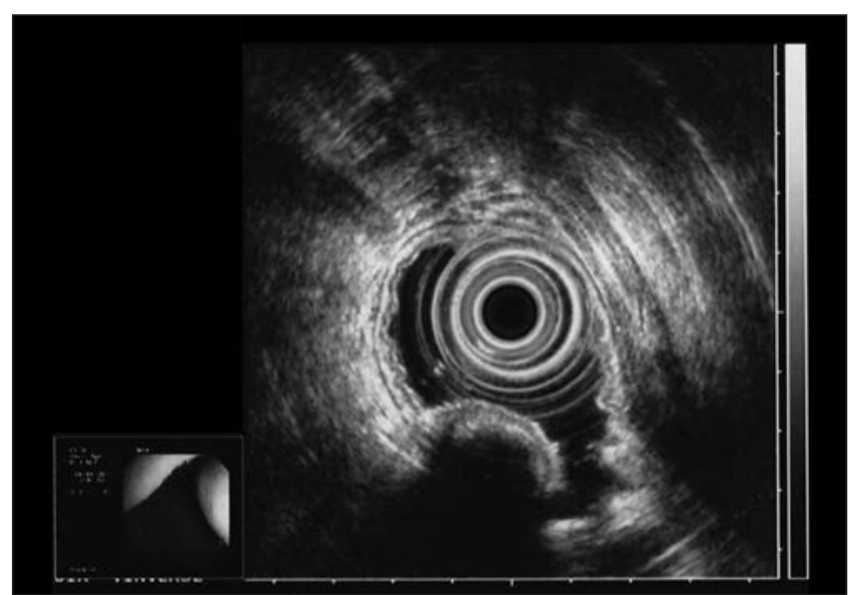

Figure 2) Radial endoscopic ultrasound of the stomach showing a focal hypoechoic lesion involving the mucosal layers. Within the lesion, there are hyperechoic foci with shadowing consistent with calcifications. The depth of the lesion could not be determined due to the shadowing artifact produced by the calcifications. The remainder of the gastric wall at this level appears normal

and S100 stainings were negative. The histology was characteristic of a benign, calcifying, fibrous tumour.

\section{DISCUSSION}

Submucosal lesions are usually asymptomatic and detected incidentally on endoscopic or radiological examinations performed for unrelated indications. A retrospective study (18) suggested that the incidence of gastric submucosal lesions is $0.36 \%$. GI stromal tumours (GISTs), the most common nonepithelial tumours of the alimentary tract, originate from interstitial cells of Cajal (19,20). Most GISTs are immunohistochemically positive for CD117 (c-kit protein) and approximately $70 \%$ test positive for CD34 (20). Other mesenchymal neoplasms include smooth muscle tumours (leiomyomas and leiomyosarcomas) which are positive for the smooth muscle markers desmin and actin, schwannomas derived from nerves which are positive for S100, and vascular tumours derived from endothelial

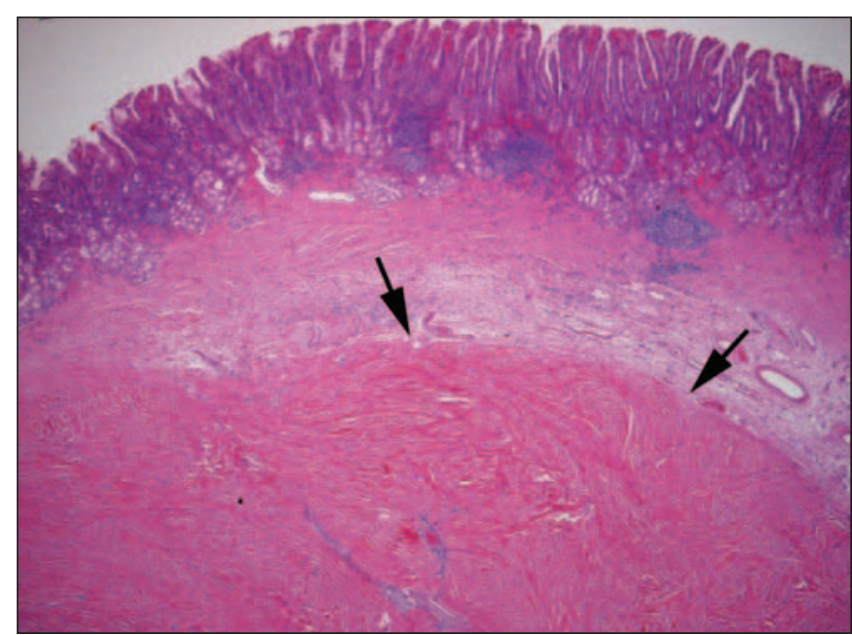

Figure 3) Tissue sections show a circumscribed fibrocollagenous nodule in the gastric wall beneath the overlying gastric antral mucosa $($ Hematoxylin and eosin stain, original magnification $\times 25$ )

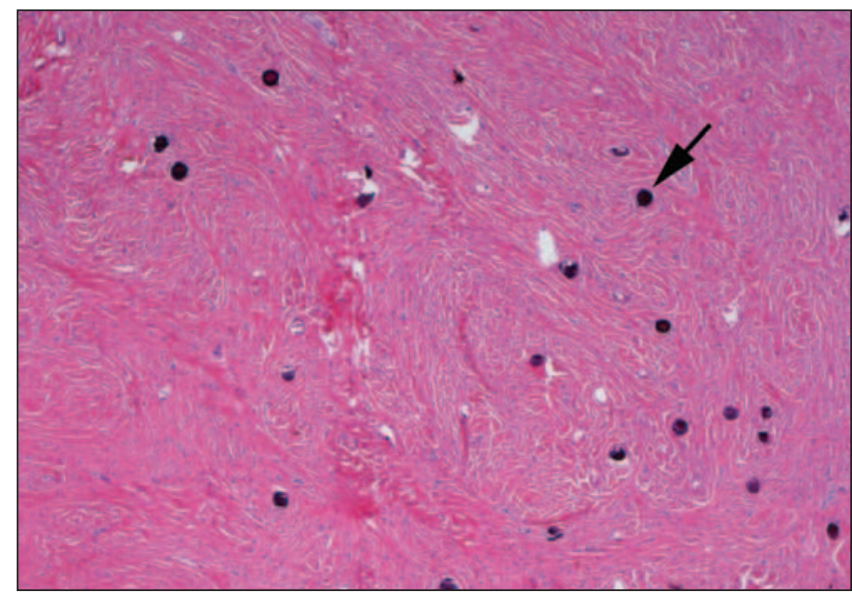

Figure 4) Higher power view of tumour showing interlacing collagen bundles with scant cellularity and abundant basophilic microcalcifications (Hematoxylin and eosin stain, original magnification $\times 50$ )

cells. Heterotopic pancreas, lipomas, cystic lesions and lymphomas comprise the rest of the gastric submucosal lesions (20).

The pathology in this case was unique and showed a parvicellular, spindle-celled tumour with a dense hyaline stroma that exhibited a negative immunoprofile for GISTs of smooth muscle and neural derivations. A calcifying fibrous tumour is a rare, benign, soft tissue tumour of fibrocytic derivation that has been reported in many body sites and appears to be more viscerotropic in older patients. To the best of our knowledge, only two similar cases $(16,17)$ have been reported in the stomach. The presence of intratumoural calcification, in the absence of degenerative changes, may be a clue for diagnosis through endoscopic ultrasonography, which was evident in our case. Although the pathogenesis of this tumour remains unknown, trauma has been implicated. Reported soft tissue tumours of this type have a benign prognosis. Although rare, calcifying fibrous tumours must be included in the lengthy differential diagnosis of a gastric mesenchymal tumour. 


\section{REFERENCES}

1. Montgomery E. Calcifying fibrous tumour. In: Fletcher CDM, Unni KK, Mertens F, eds. Pathology and Genetics of Tumours of Soft Tissue and Bone. Lyon, France: IARC Press; 2002:77-78. Kleihues P, Sobin LH, eds. World Health Organization Classification of Tumours.

2. Rosenthal NS, Abdul-Karim FW. Childhood fibrous tumor with psammoma bodies. Clinicopathologic features in two cases. Arch Pathol Lab Med 1988;112:798-800.

3. Fetsch JF, Montgomery EA, Meis JM. Calcifying fibrous pseudotumor. Am J Surg Pathol 1993;17:502-8.

4. Ben-Izhak O, Itin L, Feuchtwanger Z, Lifschitz-Mercer B, Czernobilsky B. Calcifying fibrous pseudotumor of mesentery presenting with acute peritonitis: Case report with immunohistochemical study and review of literature. Int J Surg Pathol 2001;9:249-53.

5. Kocova L, Michal M, Sulc M, Zamecnik M. Calcifying fibrous pseudotumour of visceral peritoneum. Histopathology 1997;31:182-4

6. Nascimento AF, Ruiz R, Hornick JL, Fletcher CD. Calcifying fibrous 'pseudotumor': Clinicopathologic study of 15 cases and analysis of its relationship to inflammatory myofibroblastic tumor. Int J Surg Pathol 2002;10:189-96.

7. Weynand B, Draguet AP, Bernard P, Marbaix E, Galant C. Calcifying fibrous pseudotumour: First case report in the peritoneum with immunostaining for CD34. Histopathology 1999;34:86-7.

8. Chen KT. Familial peritoneal multifocal calcifying fibrous tumor. Am J Clin Pathol 2003;119:811-5.

9. Hainaut P, Lesage V, Weynand B, Coche E, Noirhomme P. Calcifying fibrous pseudotumor (CFPT): A patient presenting with multiple pleural lesions. Acta Clin Belg 1999;54:162-4.
10. Pinkard NB, Wilson RW, Lawless N, et al. Calcifying fibrous pseudotumor of pleura. A report of three cases of a newly described entity involving the pleura. Am J Clin Pathol 1996;105:189-94.

11. Mito K, Kashima K, Daa T, et al. Multiple calcifying fibrous tumors of the pleura. Virchows Arch 2005;446:78-81.

12. Jang KS, Oh YH, Han HX, et al. Calcifying fibrous pseudotumor of the pleura. Ann Thorac Surg 2004;78:e87-8.

13. Dumont P, de Muret A, Skrobala D, Robin P, Toumieux B. Calcifying fibrous pseudotumor of the mediastinum. Ann Thorac Surg 1997;63:543-4.

14. Soyer T, Ciftci AO, Gucer S, Orhan D, Senocak ME. Calcifying fibrous pseudotumor of lung: A previously unreported entity. J Pediatr Surg 2004;39:1729-30.

15. Eftekhari F, Ater JL, Ayala AG, Czerniak BA. Case report: Calcifying fibrous pseudotumour of the adrenal gland. Br J Radiol 2001;74:452-4.

16. Delbecque K, Legrand M, Boniver J, Lauwers GY, de Leval L. Calcifying fibrous tumour of the gastric wall. Histopathology 2004;44:399-400.

17. Puccio F, Solazzo M, Marciano P, Benzi F. Laparoscopic resection of calcifying fibrous pseudotumor of the gastric wall. A unique case report. Surg Endosc 2001;15:1227.

18. Hedenbro JL, Ekelund M, Wetterberg P. Endoscopic diagnosis of submucosal gastric lesions. The results after routine endoscopy. Surg Endosc 1991;5:20-3.

19. Polkowski M, Butruk E. Submucosal lesions. Gastrointest Endosc Clin N Am 2005;15:33-54.

20. Sugar I, Forgacs B, Istvan G, Bognar G, Sapy Z, Ondrejka P. Gastrointestinal stromal tumors (GIST). Hepatogastroenterology 2005;52:409-13. 


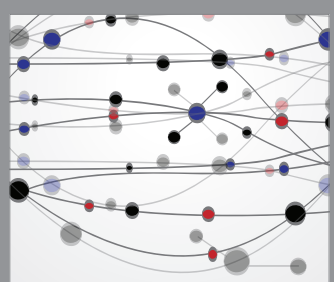

The Scientific World Journal
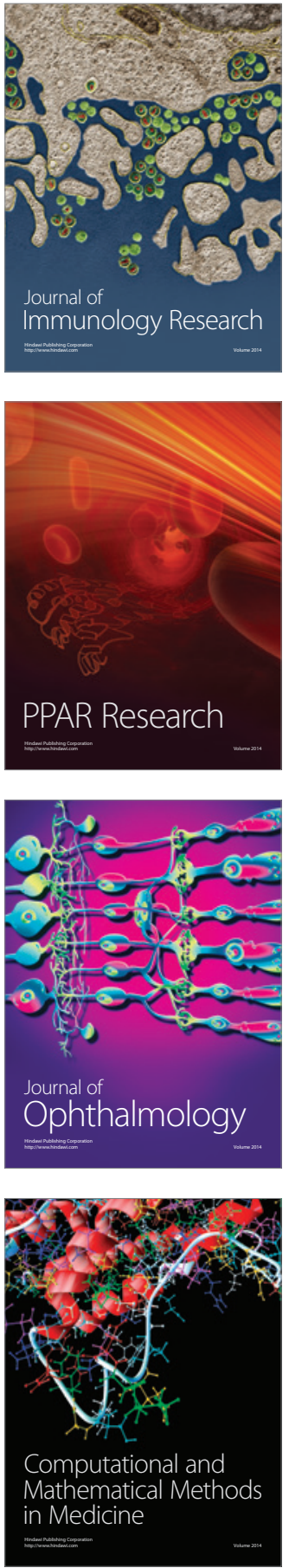

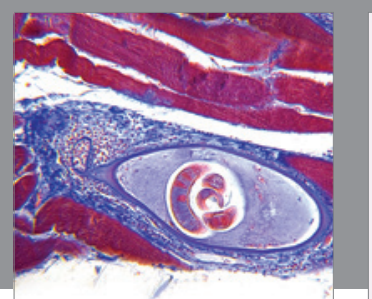

Gastroenterology Research and Practice

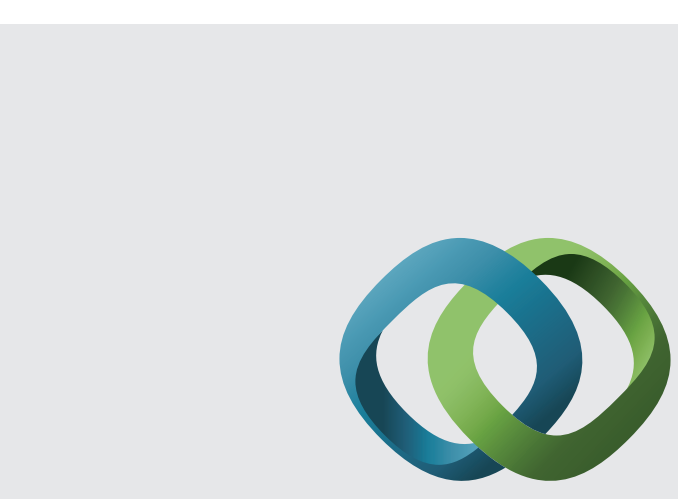

\section{Hindawi}

Submit your manuscripts at

http://www.hindawi.com
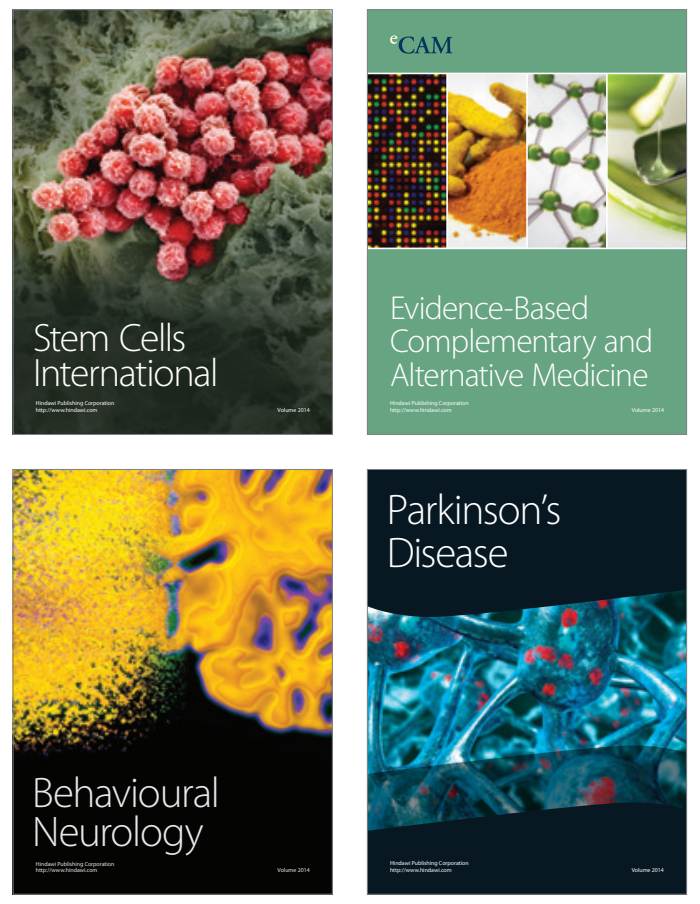
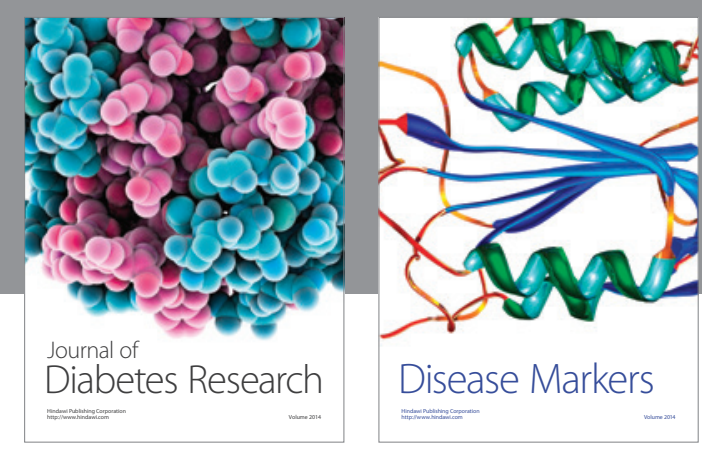

Disease Markers
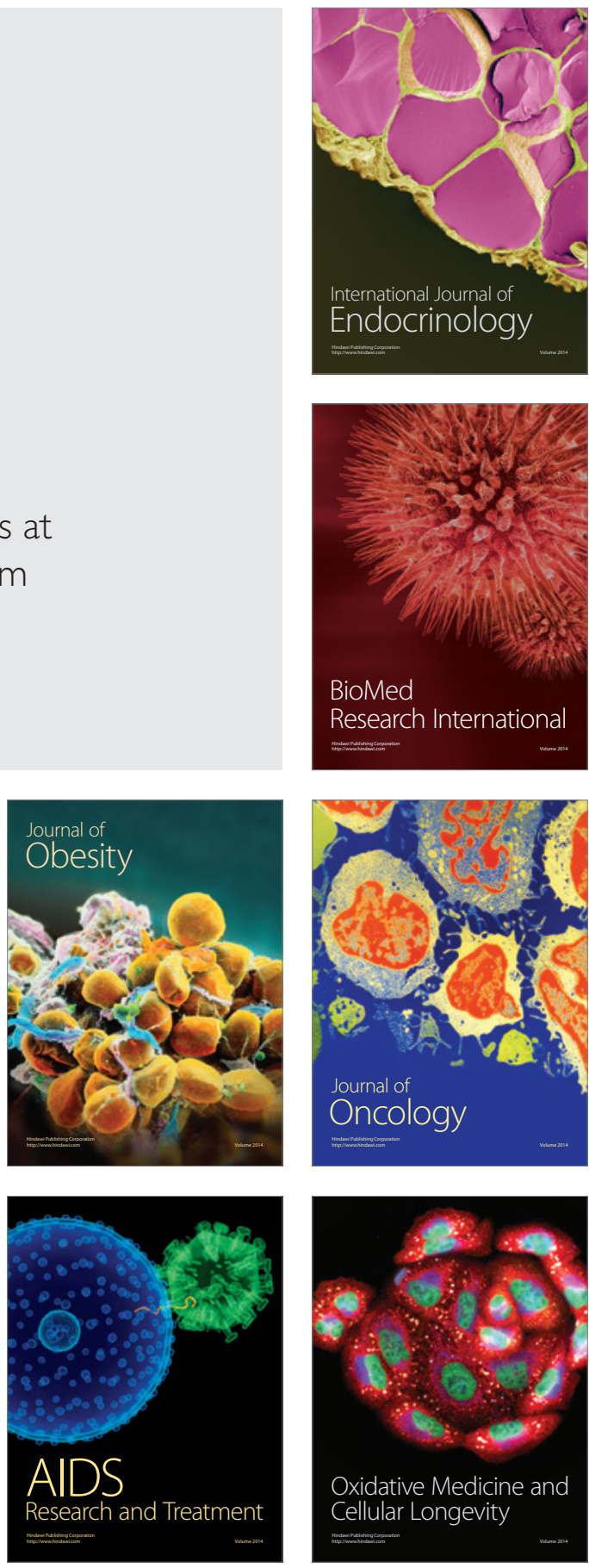